\title{
Development and Validation of SYBR Green-Based qPCR Technique of Detection and Quantification of Salmonella enterica
}

\author{
Rodica Sturza ${ }^{*}$, Valentin Mitin², Irina Mitina ${ }^{2}$, Alexandra Buga1, Dan Zgardan'1, Emilia Behta1 \\ ${ }^{1}$ Technical University of Moldova, Chisinau, Republic of Moldova \\ ${ }^{2}$ Institute of Genetics, Physiology and Plant Protection, Chisinau, Republic of Moldova \\ Email: ^rodica.sturza@chim.utm.md
}

How to cite this paper: Sturza, R., Mitin, V., Mitina, I., Buga, A., Zgardan, D. and Behta, E. (2021) Development and Validation of SYBR Green-Based qPCR Technique of Detection and Quantification of Salmonella enterica. Food and Nutrition Sciences, 12, 997-1007.

https://doi.org/10.4236/fns.2021.1211073

Received: October 5, 2021

Accepted: November 2, 2021

Published: November 5, 2021

Copyright $\odot 2021$ by author(s) and Scientific Research Publishing Inc. This work is licensed under the Creative Commons Attribution International License (CC BY 4.0).

http://creativecommons.org/licenses/by/4.0/

\begin{abstract}
Salmonella enterica serovars is a leading cause of human gastroenteritis, and the incidence of salmonellosis is constantly increasing, causing millions of infections and many deaths annually. The detection of the pathogen in optimal terms is an essential factor for reducing the impact on the human body. In this work, SYBR Green I-based qPCR method of detection and quantification of Salmonella enterica was developed and validated. For detection of Salmonella enterica subsp. enterica, two pairs of primers were designed using publically available Primer-BLAST software. Primer efficiency was calculated by establishing a standard curve. The specificity, sensitivity, accuracy, and precision of PCR results were tested. Both primer pairs showed an acceptable performance, proving the developed techniques were sensitive, reliable and precise. The validated $\mathrm{qPCR}$ technology has a good potential to replace the traditional culture method in microbial diagnosis.
\end{abstract}

\section{Keywords}

Dilution, DNA, Primer, Real-Time PCR, Salmonella enterica

\section{Introduction}

In recent decades, according to World Health Organization (WHO), the incidence of Salmonella infection (salmonellosis) has been increasing worldwide. Contamination of food with Salmonella spp. and, as a consequence, the development of salmonellosis is a serious threat that requires great attention to the control of the microbiological purity of food, the development of quick and rapid, accurate methods for its detection. 
According to the Bergey's Manual of Systematic Bacteriology, Salmonella belongs to the Enterobacteriaceae family, genus-Salmonella, which includes 2 species: Salmonella bongori and Salmonella enterica [1]. S. enterica subdivided into six subspecies with about 2500 serovars (serotypes) [2]. These serovars can cause illnesses in human ranging from gastroenteritis to typhoid fever which kills around 500,000 people worldwide per year [3].

The source of salmonellosis, most often, are eggs (up to $90 \%$ of cases of salmonellosis are associated with the consumption of raw or insufficiently cooked eggs), meat and dairy products, and, to a lesser extent, fish and fish products, as well as plant products. Salmonella is relatively stable in the external environment and is well preserved in room dust (almost up to three months), in open water (11 to 120 days), in meat and sausages ( 2 - 6 months), in frozen meat (more than six months), in milk at room temperature for up to 10 days and in the refrigerator for up to 20 days; in butter (52 - 128 days); in eggs (over a year), on eggshells (24 days). At $70^{\circ} \mathrm{C}$, salmonella die within 5 - 10 minutes, in the thickness of meat they withstand boiling for several hours. In meat stored in a refrigerator at a low above zero temperature, salmonella not only survive, but are also able to reproduce [4].

Recently, salmonella serotypes have become widespread, characterized by resistance to many modern common antibiotics and disinfectants, as well as increased heat resistance [5].

It has been extensively reported that classical microbiological methods, even though reliable, are lengthy and tedious. In this sense molecular applications, relies on the detection of specific Salmonella genes by PCR techniques, such as Real-Time PCR [6] [7], which have greatly allowed the reduction in the time needed to achieve the final result and to help control the spread of disease [8].

For designing a reliable PCR assay, it is necessary to pick a good target gene for PCR amplification. Several target genes of Salmonella have been reported, such as invA [6] [7] [9], sdiA, fliC, fliB, sefB, hilA [10] [11] [12] [13] [14].

The invA gene lies at centisome 63 region of the Salmonella chromosome and is widely used as a target in PCR assays for Salmonella detection [10].

The invA gene usually codes for a protein of the inner bacterial membrane, which is responsible for the invasion of the intestinal cells of the host [4] and is promising for primer design since it contains conservative and well characterized sequences. In order to validate the PCR assays of Salmonella molecular detection it is necessary to test specificity, sensitivity, accuracy, and precision of results [15].

\section{Materials and Methods}

\subsection{Materials}

As Salmonella enterica DNA standard, microbial DNA standard from Salmonella enterica, (Sigmaaldrich MBD0005) was used. For primer specificity check, DNA from liquid cultures of Escherichia coli, Staphylococcus aureus, Listeria 
monocytogenes was purified using SDS-based method. Briefly, the cells from 1 $\mathrm{ml}$ culture were pelleted by centrifugation and re-suspended in $0.6 \mathrm{~mL}$ of the Extraction buffer (Tris- $\mathrm{HCl} 0.2 \mathrm{M}$ pH 8.0, NaCl 0.25M, Na2EDTA 0.025M, SDS $5 \% \mathrm{w} / \mathrm{v}$ ) and heated at $65^{\circ} \mathrm{C}$ for 1 hour. Then the lysate was centrifuged, supernatant collected to a fresh $1.7 \mathrm{ml}$ tube, followed by chlorophorm extraction and ethanol precipitation. The pellet was washed with $70 \%$ ethanol, air dried and dissolved in $100 \mathrm{ul}$ of deionized water; $2 \mu \mathrm{L}$ of the resulting DNA solution was used per PCR reaction. The qualitative and quantitative verification of the isolated DNA was made by spectrophotometric analyses at Genova Nano Micro-volume spectrophotometer.

\subsection{Methods}

The method used was quantitative real-time PCR (qPCR). qPCR allows precise quantification of specific nucleic acids in a complex solution by fluorescent detection of labeled PCR products. In a real-time PCR, a positive reaction is detected by accumulation of a fluorescent signal. For the experiments, we used SYBR Green I nonspecific dye as the fluorescent agent (Applied byosystems). The quantification cycle $(\mathrm{Cq})$ represents the number of cycles required for the fluorescent signal to cross the threshold (i.e., to pass the background level). Cq levels are inversely proportional to the amount of target nucleic acid in the sample. The lower the $\mathrm{Cq}$ level the higher is the concentration of target nucleic acid in the sample. We used 40 cycles of amplification. Figure 1 showed the cycling conditions used in this work.

qPCR was carried out on a Real-Time PCR Detection Systems CFX96 TouchTM BIORAD. qPCR conditions were as recommended by SybrGreen producer (Applied Biosystems) - initial incubation at $50^{\circ} \mathrm{C}$ for 2 minutes, initial denaturation at $95^{\circ} \mathrm{C}$ for 2 minutes, and alternation at $95^{\circ} \mathrm{C}$ for 15 seconds and $60^{\circ} \mathrm{C}$ for 1 minute for 40 cycles. For melting curve construction, samples were heated at $95^{\circ} \mathrm{C}$ for 15 seconds, then incubated at $60^{\circ} \mathrm{C}$ for 1 minute $\left(1.6^{\circ} \mathrm{C} / \mathrm{s}\right.$ ramp rate),

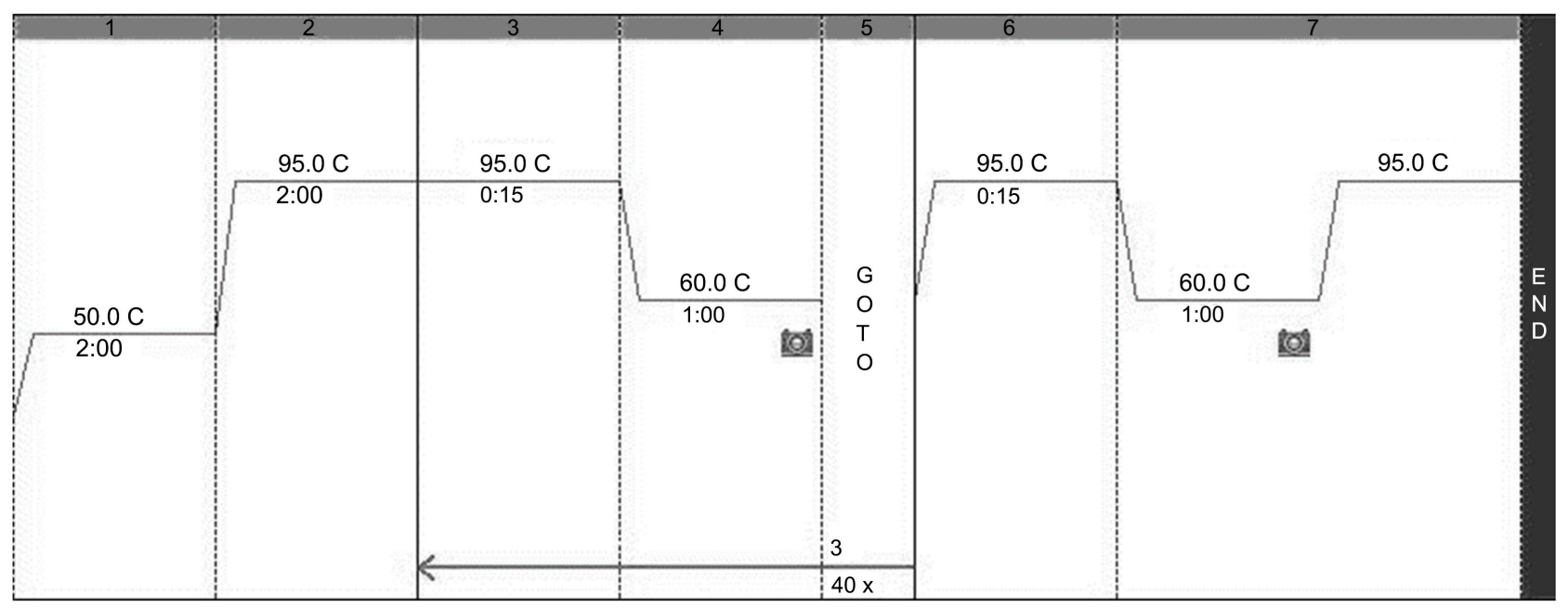

Figure 1. Temperature cycling conditions. 
then heated at $95^{\circ} \mathrm{C}$ for 15 seconds $\left(0.15^{\circ} \mathrm{C} / \mathrm{s}\right.$ ramp rate). Cycling conditions are shown in Figure 1. The detection was done at SYBR channel.

\section{Results and Discussion}

\subsection{Primer Design}

For detection of Salmonella enterica subsp. enterica, two pairs of home designed primers were developed. Primers were designed using Primer-BLAST software, available at https://www.ncbi.nlm.nih.gov/tools/. During primer design, the default values were used for most parameters except for PCR product size which was set to the value of $70-200$, Primer melting temperatures (Tm) was set up to be within 60 for Min, 61 for Opt, 63 for Max; Max GC in primer 3' end was set to the value of 2, Max Self Complementarity and Max Pair Complementarity-5 for the parameter Any. The template used was the nucleic acid sequence LC111465.1 for invA gene (invasive antigen A) from GenBank. Designing primers targeting this gene can be a good choice, due to its conservative and well characterized sequences.

Table 1 showed sequences and characteristics of the primers used in this work. Primer pairs se21-22 and se23-24 were used for qPCR analysis.

BLAST analysis of the primers showed that these primers were capable of recognizing a vast number of Salmonella enterica serovars, including Typhi, Adjame, Typhimurium, Infantis, Worthington, Albany, Heidelberg, Enteritidis, Anatum, Kentucky, Weltevreden etc.

\subsection{Primer Experimental Testing and Validation}

\section{Primer specificity check}

Primer specificity is the ability of primers to recognize only target DNA rather than unrelated DNA sequences.

First, the specificity of the primers was checked bioinformatically (in silico) to assure that no overlapping with other species is detected by BLAST. Second, the specificity of the primers was checked experimentally (in vitro). Purified DNA samples extracted from Escherichia coli, Staphylococcus aureus, Listeria monocytogenes, as well as standard DNA of Salmonella enterica were used as a template

Table 1. The sequences and characteristics of the primers.

\begin{tabular}{|c|c|c|c|c|c|c|c|}
\hline Primer & Sequence $\left(5^{\prime}->3^{\prime}\right)$ & $\begin{array}{c}\text { Template } \\
\text { strand }\end{array}$ & Length & $\operatorname{Tm}$ & GC\% & Self compl. & Self 3' compl. \\
\hline se21- & GCTTCCAGTTGGTCCAGCAT & Plus & 20 & 60.61 & 55 & 5 & 3 \\
\hline 22 & CGGGAGCTTGGCTATGTGTT & Minus & 20 & 60.39 & 55 & 4 & 0 \\
\hline Product length & 131 & & & & & & \\
\hline se23- & CGTGGCATGTCTGAGCACTT & Plus & 20 & 60.95 & 55 & 4 & 3 \\
\hline 24 & ACGCATGAAGAGGGGGAGAA & Minus & 20 & 60.91 & 55 & 4 & 0 \\
\hline Product length & 198 & & & & & & \\
\hline
\end{tabular}


in PCR with the tested pairs of primers. Figure 2 showed the results obtained with primer pair se21-22 (Figure 2(a)) and primer pair se23-24 (Figure 2(b)).

Neither of the primer pairs amplified irrelevant DNA sequences. One can see, that the amplification is observed only in the samples with Salmonella enterica standard DNA as a template, while no amplification occurs in the no template control and irrelevant DNA samples.

\section{Primer efficiency}

Ideally, if the amplification efficiency is $100 \%$, the amount of newly synthesized PCR amplicon doubles each cycle. The efficiency of the reaction can be estimated from the slope of the standard curve. Practically, primers are suitable for real-time PCR analysis with the efficiencies $90 \%-110 \%$.

Primer efficiency was calculated by establishing the standard curve. The ranges of the standard curve of Salmonella enterica standard DNA were $2 \mathrm{ng} / \mathrm{ul}-2 \times$ $10^{6} \mathrm{ng} / \mathrm{ul}$, each standard was tested in triplicate. Figure 3 showed the standard curves for the primer pair se21-22 (Figure 3(a)) and se23-24 (Figure 3(b)).

Using the standard curve and the online primer efficiency calculator (https://www.thermofisher.com/ro/en/home/brands/thermo-scientific/molecula r-biology/molecular-biology-learning-center/molecular-biology-resource-library /thermo-scientific-web-tools/qpcr-efficiency-calculator.html), primer efficiency was calculated. For primer pair se21-22, primer efficiency was $106.81 \%$. For

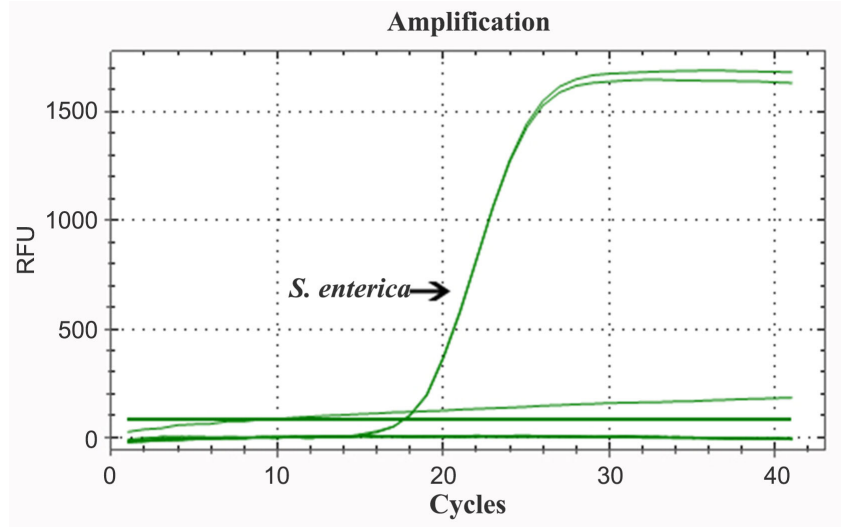

(a)

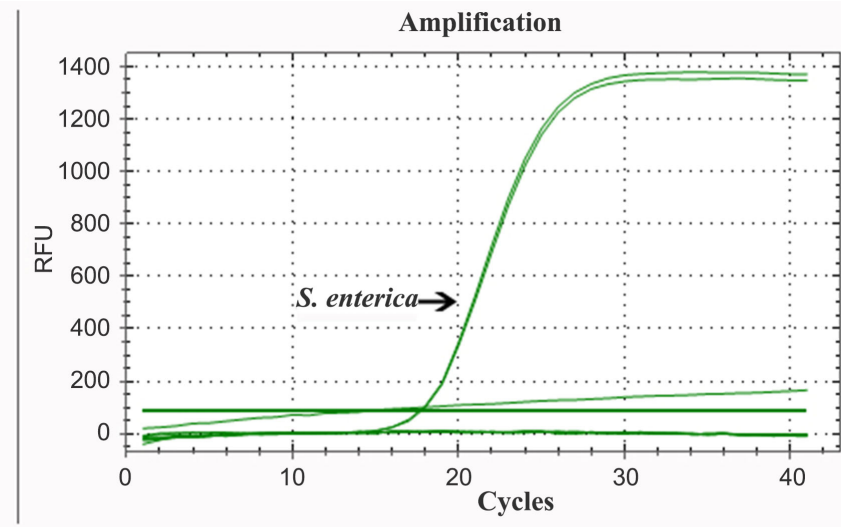

(b)

Figure 2. Primer specificity test se21-22 (a) and se23-24 (b). Only Salmonella enterica DNA shows the amplification curve.

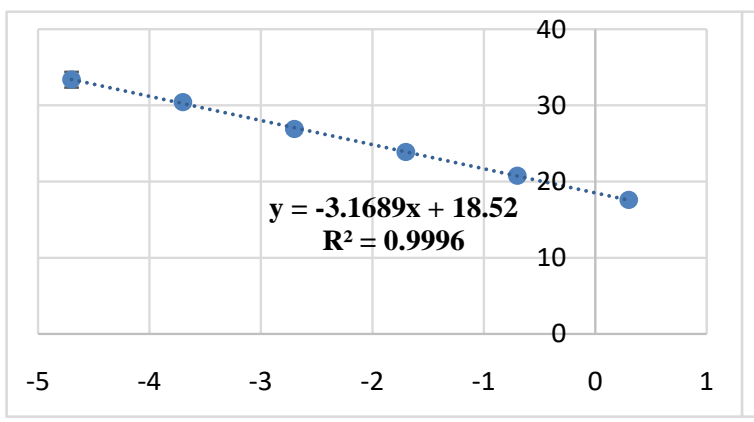

(a)

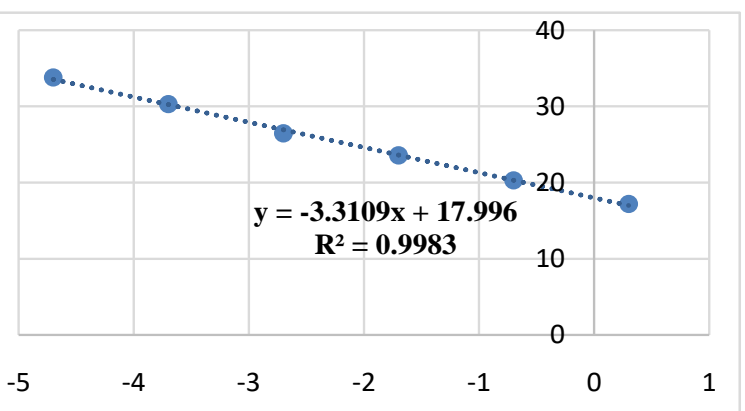

(b)

Figure 3. The standard curves for the primer pairs se21-22 (a) and se23-24(b). 
primer pair se23-24, primer efficiency was $100.46 \%$, which makes both primer pairs suitable for use in $\mathrm{qPCR}$.

\section{$L O D$ and $L O Q$}

Generally, the LOD (limit of detection) is defined as the lowest amount of analyte, which can be detected with a more than stated percentage of confidence, but not necessarily quantified as an exact value [16]. Another definition describes LOD as the lowest concentration level which can be determined as statistically different from blank. However, in PCR, for the limited concentration of template DNA (analyte), the output of the reaction will be either amplification, or no amplification at all, making it impossible to set a cut-off value after which the sample will be considered positive [17].

Since the definitions reported were described for chemical methods and are not perfectly suited for PCR, other approaches have been proposed. It is generally accepted to consider the LOD as the minimum concentration of nucleic acid or number of cells, which always gives a positive PCR result in over $95 \%$ of replicas tested [18].

In this case, the LOD was determined by establishing the standard curve and analyzing which concentration gives a positive PCR signal in over $95 \%$ of the replicas. The ranges of the standard curve of Salmonella enterica standard DNA were $2 \mathrm{ng} / \mu \mathrm{l}-2 \times 10^{6} \mathrm{ng} / \mu \mathrm{l}$, each standard was tested in triplicate. The amount of $2 \times 10^{-5} \mathrm{ng} / \mu \mathrm{l}$ was reliably detectable throughout the assay with both primer pairs (Figure 4).

The LOQ (limit of quantification) was defined as the smallest amount of analyte, which can be measured and quantified with defined precision and accuracy under the experimental conditions by the method under validation [16]. For qPCR, the LOQ is determined as the lowest concentration of analyte, which gives a variability (CV, coefficient of variation) below $25 \%$. In this assay, LOQ was equal to LOD, and was $2 \times 10^{-5} \mathrm{ng} / \mu \mathrm{l}$ for both primer pairs.

\section{Precision}

Precision is defined as the degree of agreement of measurements under specified conditions. Intra-assay precision was determined from experiment results in an

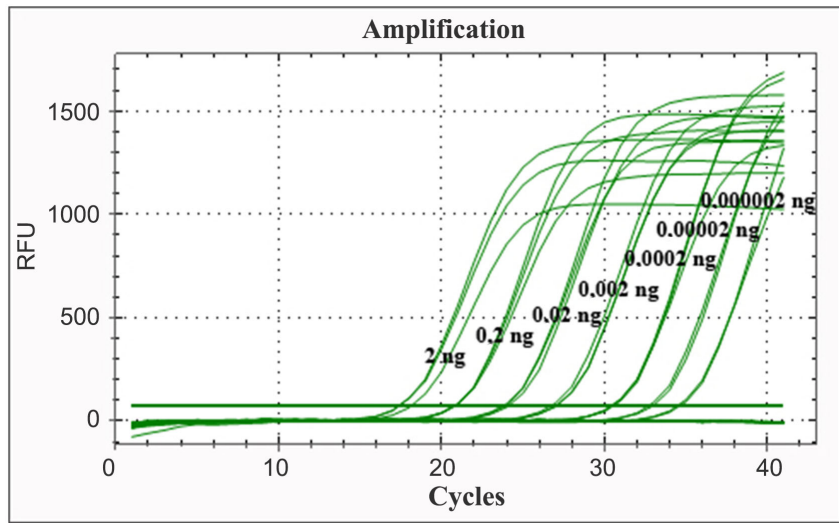

(a)

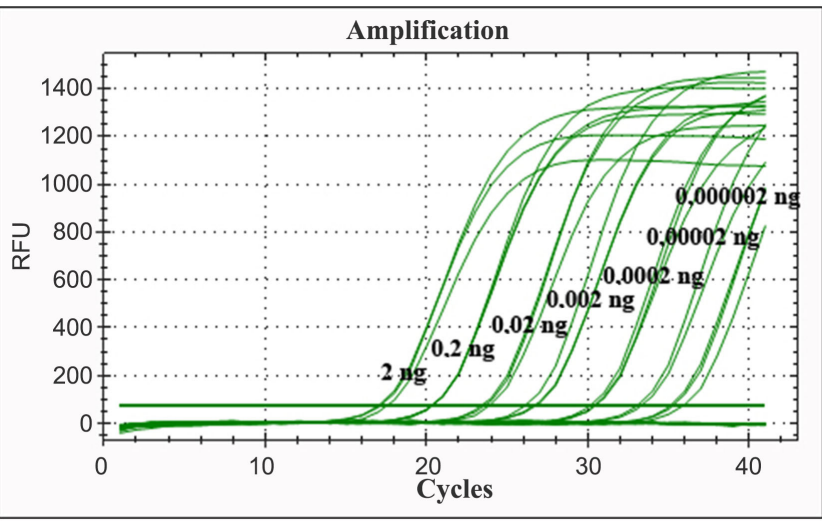

(b)

Figure 4. Determination of detection limit for primer pair se21-22 (a) and se23-24 (b). 
individual run. The standard deviation (SD) and coefficient of variation (CV) of each standard were from 0.05 to 1.03 cycles and $2.5 \%$ to $3.1 \%$. For primer pair se21-22 and $0.02-1.13$ cycles and $0.1 \%$ to $3.35 \%$ for primer pair se23-24. Table 2 and Table 3 showed the results of intra-assay precision tests for both primer pairs.

Inter-assay precision was determined from experimental results from three different runs on three different days. The SD and CV were $0.23-0.8$ and 1.34 to $2.9 \%$. For primer pair se21-22 and $0.27-0.97$ cycles and $1.53 \%$ to $3.15 \%$ for primer pair se23-24. Table 4 and Table 5 showed the results of inter-assay precision tests for both primer pairs.

Table 2. Intra-assay precision (repeatability) test for primer pair se21-22.

\begin{tabular}{cccc}
\hline Standard, $\mathrm{ng} / \mu \mathrm{l}$ & Mean Ct $(\mathrm{n}=3)$ & STDEV & Coefficient variation \\
\hline 2 & 17.59719888 & 0.438542 & 2.492112398 \\
0.2 & 20.7553349 & 0.053635 & 0.258415242 \\
0.02 & 23.88458118 & 0.186543 & 0.781017251 \\
0.002 & 26.89655218 & 0.208508 & 0.775220683 \\
0.0002 & 30.4138247 & 0.070077 & 0.230410339 \\
0.00002 & 33.38192428 & 1.038433 & 3.110765388 \\
\hline
\end{tabular}

Table 3. Intra-assay precision (repeatability) test for primer pair se23-24.

\begin{tabular}{cccc}
\hline Standard, ng/ $\mu \mathrm{l}$ & Mean Ct $(\mathrm{n}=3)$ & STDEV & Coefficient variation \\
\hline 2 & 17.20860213 & 0.270594865 & 1.572439543 \\
0.2 & 20.29236189 & 0.024829105 & 0.122356902 \\
0.02 & 23.58279697 & 0.254664027 & 1.079872025 \\
0.002 & 26.47513677 & 0.351875914 & 1.329080629 \\
0.0002 & 30.30124086 & 0.157424314 & 0.519530916 \\
0.00002 & 33.80120295 & 1.13293754 & 3.351766923 \\
\hline
\end{tabular}

Table 4. Inter-assay precision (intermediate precision) test for primer pair se21-22.

\begin{tabular}{cccccc}
\hline Pair se21-22 & \multicolumn{5}{c}{ Mean Ct } \\
\hline Standard, ng/ $\mu \mathrm{l}$ & Day 1 & Day2 & Day3 & STDEV & CV, \% \\
\hline 2 & 17.67344 & 17.5972 & 17.38514 & 0.149387 & 0.8511151 \\
0.2 & 21.17401 & 20.75533 & 20.86401 & 0.217252 & 1.0379384 \\
0.02 & 24.08814 & 23.88458 & 24.42158 & 0.271105 & 1.1234537 \\
0.002 & 27.60883 & 26.89655 & 28.02483 & 0.570585 & 2.0740953 \\
0.0002 & 30.78307 & 30.41382 & 31.76068 & 0.69595 & 2.2460243 \\
0.00002 & 34.17652 & 33.38192 & 35.15967 & 0.890538 & 2.6009194 \\
\hline
\end{tabular}


Table 5. Inter-assay precision (intermediate precision) test for primer pair se23-se24.

\begin{tabular}{cccccc}
\hline Pair se23-24 & \multicolumn{5}{c}{ Mean Ct } \\
\hline Standard, ng/ $\mu \mathrm{l}$ & Day 1 & Day 2 & Day3 & STDEV & CV, \% \\
\hline 2 & 17.67044 & 17.2086 & 17.19989 & 0.269193 & 1.5506851 \\
0.2 & 21.11432 & 20.29236 & 20.73872 & 0.411485 & 1.9864003 \\
0.02 & 24.12672 & 23.5828 & 24.28787 & 0.369449 & 1.5394268 \\
0.002 & 27.51393 & 26.47514 & 28.8854 & 0.73097 & 2.6783822 \\
0.0002 & 30.53868 & 30.30124 & 32.09845 & 0.97632 & 3.1515081 \\
0.0002 & 34.23234 & 33.8012 & 34.8602 & 0.532535 & 1.5526751 \\
\hline
\end{tabular}

\section{Accuracy}

Accuracy is defined as a degree of conformity of a value generated by a procedure to the assumed or accepted true value [19]. In other words, it shows how close are the experimental values to the reference values.

For accuracy measurement, DNA of Salmonella enterica of three different concentrations $(0.04,0.01$ and $0.025 \mathrm{ng})$ was used as a template in eal-time PCR. The real-time PCR experiments were carried out by 9 replicates on different days.

Table 6 showed the percentage recovery for pair of primers se21-22, and Table 7 showed the percentage recovery for pair of primers se23-24. The average recovery was $81.8 \%-111.4 \%$ for $s e 21-22$ and $63.4 \%$ - $99.8 \%$ for pair of primers se23-24.

\section{Linearity}

The linearity of this method for both primer paiars was evaluated by calculating coefficients of determination $\left(\mathrm{R}^{2}\right)$. Three standard curves were created by plotting mean $\mathrm{C}_{\mathrm{T}}$ values against the DNA concentration. Data from three independent experiments were used for building the standard curves. Figure 5 showed the standard curves of three independent experiments for the primer pair se21-22. The $\mathrm{R}^{2}$ of the standard curves exceeded 0.99 , which meets the accepted criterion the $\mathrm{R}^{2}>0.98$.

Figure 6 showed the standard curves of three independent experiments for the primer pair se23-24. The $\mathrm{R}^{2}$ of the standard curves exceeded 0.99 , which met the accepted criterion the $\mathrm{R}^{2}>0.98$.

At present, conventional culture-based methods are considered to be gold standard for detecting food-borne pathogenic bacteria. However, these methods have a number of disadvantages. They are time-consuming and labor intensive. Besides, it is difficult to use them for quantification of the pathogenic bacteria. Thus, there is a need for rapid, sensitive and specific methods suitable for high throughput analysis and capable of quantifying the disease-causing bacteria.

In this paper we describe development and validation of SYBR Green-based qPCR technique of detection and quantification of Salmonella enterica. This technique allows for a high throughput processing of samples, produces results within hours, is inexpensive and available. 
Table 6. Accuracy test for primer pair se21-se22.

\begin{tabular}{ccccc}
\hline $\begin{array}{c}\text { Pair } \\
\text { se21-22 }\end{array}$ & $\begin{array}{c}\text { concentration, } \\
\text { ng/ul }\end{array}$ & $\begin{array}{c}\text { measured, } \\
\text { ng/ul }\end{array}$ & $\begin{array}{c}\text { average } \\
\text { recovery, } \%\end{array}$ & $\begin{array}{c}\mathrm{CV}, \\
\%\end{array}$ \\
\hline 0.02 & 0.022279742 & 111.4 & 0.929436 \\
0.005 & 0.00491326 & 98.3 & 1.4093 \\
& 0.00125 & 0.001022459 & 81.8 & 3.995766 \\
\hline
\end{tabular}

Table 7. Accuracy test for primer pair se23-24.

\begin{tabular}{ccccc}
\hline $\begin{array}{c}\text { Pair } \\
\text { se23-24 }\end{array}$ & $\begin{array}{c}\text { concentration, } \\
\text { ng/ul }\end{array}$ & $\begin{array}{c}\text { measured, } \\
\text { ng/ul }\end{array}$ & $\begin{array}{c}\text { average } \\
\text { recovery, } \%\end{array}$ & $\begin{array}{c}\mathrm{CV}, \\
\%\end{array}$ \\
\hline 0.02 & 0.019951833 & 99.8 & 0.999474 \\
0.005 & 0.004585367 & 91.7 & 1.493163 \\
& 0.00125 & 0.000792106 & 63.4 & 2.492201 \\
\hline
\end{tabular}

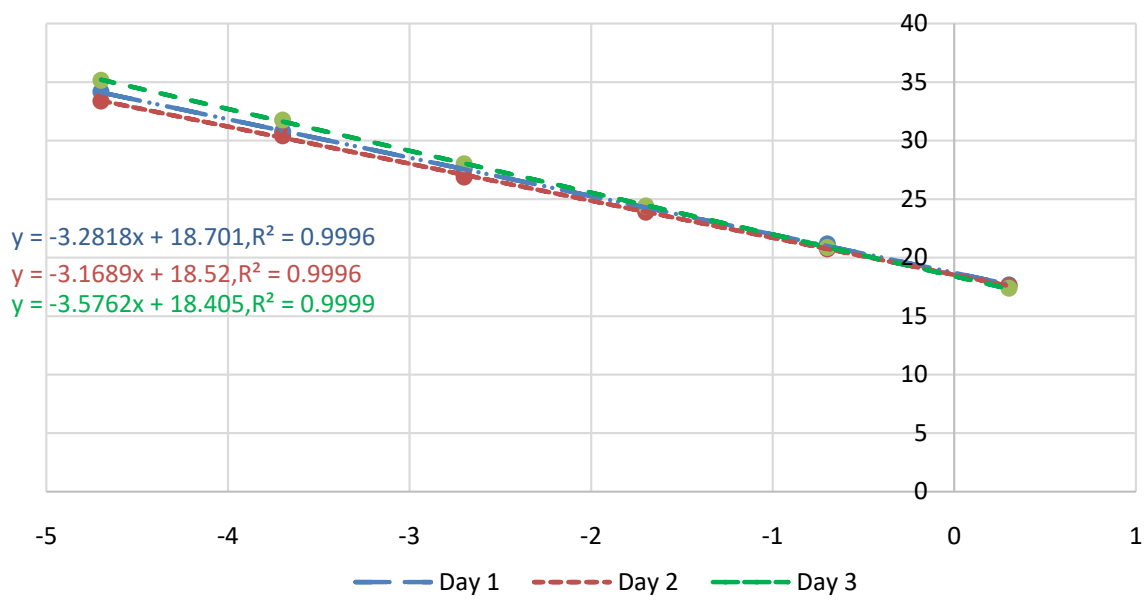

Figure 5. The standard curves of three independent experiments for the primer pair se21-22.

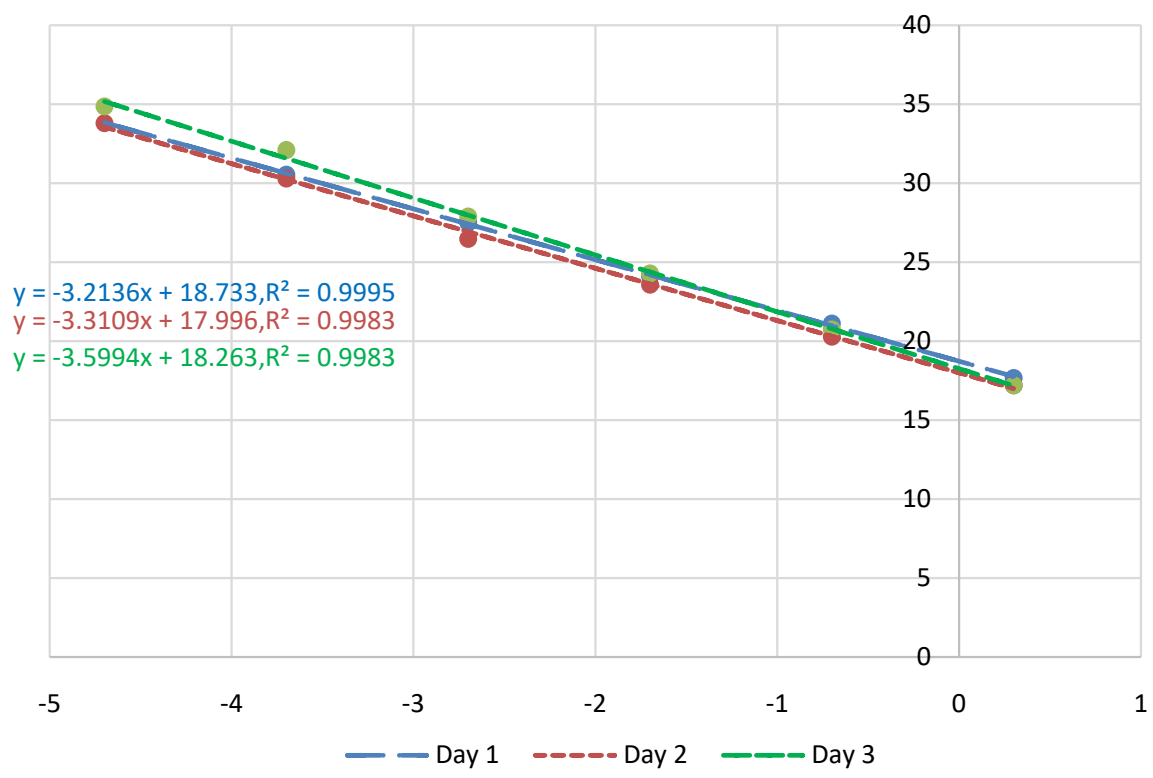

Figure 6. The standard curves of three independent experiments for the primer pair se23-24. 
qPCR-based techniques are a simple and rapid alternative to traditional culturing methods of pathogen detection in food samples. They are becoming increasingly popular due to the fast progress in sequencing techniques, and increasing number of genomic sequences of various pathogens available in open access databases. These advances make it possible to design primers to virtually any organism. Moreover, qPCR-based methods can be designed not only for detection of a pathogen and its quantification, but also for serovar typing.

\section{Conclusion}

In this work, we developed and validated a sensitive, reliable and precise technique of detection and quantification of Salmonella enterica based on SYBR Green qPCR method. qPCR technology has a good potential of replacing tradition culture method in microbial diagnostics, especially when fast and sensitive or high throughput diagnostics is required.

\section{Acknowledgements}

This work was funded by the State Project 20.80009.5107.09 "Improving of food quality and safety through biotechnology and food engineering", running at Technical University of Moldova.

\section{Conflicts of Interest}

The authors declare no conflicts of interest regarding the publication of this paper.

\section{References}

[1] Boone, D., Castenholz, R. and Garrity, G. (2001) Bergey's Manual of Systematic Bacteriology. 2nd Edition, Part 2, Springer, New York, 305-1106. https://doi.org/10.1007/978-0-387-21609-6

[2] Bahrani-Mougeot, F., Scobey, M. and Sansonetti, P. (2009) Enteropathogenic Infections. In: Schaechter, M., Ed., Encyclopedia of Microbiology, Academic Press, Oxford, 329-343. https://doi.org/10.1016/B978-012373944-5.00224-8

[3] Primerdesign Ltd. (2018) Salmonella enterica. Invasine A Gene (InvA) Genesig Advanced Kit. https://www.genesig.com/assets/files/s enterica.pdf

[4] Mąka, L. and Popowska, M. (2016) Antimicrobial Resistance of Salmonella spp. Isolated from Food. Annals of the National Institute of Hygiene, 67, 343-358.

[5] Popa, G. and Papa, M.I. (2021) Salmonella spp. Infection-A Continuous Threat Worldwide. GERMS, 11, 88-96. https://doi.org/10.18683/germs.2021.1244

[6] Anderson, A., Pietsch, K., Zucker, R., Mayr, A., Müller-Hohe, E., Messelhäusser, U., Sing, A., Busch, U. and Huber, I. (2011) Validation of a Duplex Real-Time PCR for the Detection of Salmonella spp. in Different Food Products. Food Analytical Methods, 4, 259-267. https://doi.org/10.1007/s12161-010-9142-8

[7] Bohaychuk, V., Gensler, G., McFall, M., King, R. and Renter, D. (2007) A Real-Time PCR Assay for the Detection of Salmonella in a Wide Variety of Food and FoodAnimal Matrices. Journal of Food Protection, 70, 1080-1087. https://doi.org/10.4315/0362-028X-70.5.1080 
[8] Azinheiro, S.A., Carvalho, J., Prado, M. and Garrido-Maestu, A. (2018) Evaluation of Different Genetic Targets for Salmonella enterica Serovar Enteriditis and $T y$ phimurium, Using Loop-Mediated Isothermal AMPlification for Detection in Food Samples. Frontiers in Sustainable Food Systems, 2, Article No. 5. https://doi.org/10.3389/fsufs.2018.00005

[9] Sunar, N., Stentiford, E., Stewart, D. and Fletcher, L. (2014) Molecular Techniques to Characterize the invA Genes of Salmonella spp. for Pathogen Inactivation Study in Composting. https://arxiv.org/abs/1404.5208v1

[10] Halatsi, K., Oikonomou, I., Lambiri, M., Mandilara, G., Vatopoulos, A., Kyriacou, A. (2006) PCR Detection of Salmonella spp. Using Primers Targeting the Quorum Sensing Gene sdiA. FEMS Microbiology Letters, 259, 201-207. https://doi.org/10.1111/j.1574-6968.2006.00266.x

[11] Chiu, T.H., Pang J.C., Hwang, W.Z. and Tsen, H.Y. (2005) Development of PCR Primers for the Detection of Salmonella enterica Serovar Choleraesuis Based on the fliC Gene. Journal of Food Protection, 68, 1575-1580. https://doi.org/10.4315/0362-028X-68.8.1575

[12] Silva, C., Betancor, L., García, C., Astocondor, L., Hinostroza, N., et al. (2017) Characterization of Salmonella enterica Isolates Causing Bacteremia in Lima, Peru, Using Multiple Typing Methods. PLoS ONE, 12, Article ID: e0189946. https://doi.org/10.1371/journal.pone.0189946

[13] Wang, S.J., Yeh, D.B. and Wei, C.I. (2009) Specific PCR Primers for the Identification of Salmonella enterica Serovar Enteritidis in Chicken-Related Samples. Journal of Food and Drug Analysis, 17, Article No. 9. https://doi.org/10.38212/2224-6614.2612

[14] McCabe, E., Burgess, C., Walsh, D., O’Regan, E., McGuinness, S., Barry, T., Fanning, S. and Duffy, G. (2011) Validation of DNA and RNA Real-Time Assays for Food Analysis Using the hilA Gene of Salmonella enterica Serovars. Journal of Microbiological Methods, 84, 19-26. https://doi.org/10.1016/j.mimet.2010.10.004

[15] Zheng, W., Jiang, L., Lei, Q., Yang, J., Gao, X., Wang, W., et al. (2019) Development and Validation of Quantitative Real-Time PCR for the Detection of Residual Cho Host Cell DNA and Optimization of Sample Pretreatment Method in Biopharmaceutical Products. Biological Procedures Online, 21, Article No. 17.

https://doi.org/10.1186/s12575-019-0105-1

[16] ISO (International Organization for Standardization) (2003) ISO 16140:2003 Microbiology of Food and Animal Feeding stuffs-Protocol for the Validation of Alternative Methods. https://www.iso.org/standard/30158.html

[17] Kralik, P. and Ricchi, M. (2017) A Basic Guide to Real-Time PCR in Microbial Diagnostics: Definitions, Parameters, and Everything. Frontiers in Microbiology, 8, Article No. 108. https://doi.org/10.3389/fmicb.2017.00108

[18] Nutz, S., Döll, K. and Karlovsky, P. (2011) Determination of the LOQ in Real-Time PCR by Receiver Operating Characteristic Curve Analysis: Application to qPCR Assays for Fusarium verticillioides and Fusarium proliferatum. Analytical and Bioanalytical Chemistry, 401, 717-726. https://doi.org/10.1007/s00216-011-5089-x

[19] U.S. Food and Drug Administration (2019) Guidelines for the Validation of Analytical Methods for the Detection of Microbial Pathogens in Foods and Feeds Edition 3.0 U.S. Food and Drug Administration Foods Program, U.S. Food and Drug Administration, Silver Spring. https://www.fda.gov/media/83812/download 